\title{
A New Approach for Easy Computation by using $\theta$-Matrix for solving Integer Linear Fractional Programming Problems
}

\author{
V.Seerengasamy, \\ Professor of Mathematics, \\ PSNA College of Engineering and Technology, \\ Dindigul-624 622, \\ Tamil Nadu, India.
}

\begin{abstract}
To minimize the computational effort needed in solving a Integer Linear Fractional programming problem a new approach has been proposed. Here we use $\theta$ matrix for finding the solution of the integer linear fractional programming problems.
\end{abstract}

Keywords:

Integer Linear Fractional Programming Problems, $\theta$ matrix and Promising variables.

\section{INTRODUCTION}

To solve Integer Linear Fractional Programming Problems with reduced computational effort, a new method of approach has been proposed. In this method, among the decision variables, the variables which can enter into the basis are identified and ordered based on the maximum contribution to the objective function. The ordered decision variables one by one are allowed to enter into the basis by checking whether it is still giving an improved solution.

\section{GENERAL INTEGER LINEAR FRACTIONAL PROGRAMMING PROBLEMS IN MATRIX FORM}

The general Integer Linear Fractional Programming Problems is given by

$$
\text { Extremize } \mathrm{Z}=\frac{C^{T} X+c_{0}}{D^{T} X+d_{0}}
$$

Subject to

$$
\mathrm{AX}(\leq=\geq) \mathrm{P}_{0}
$$

$\mathrm{X} \geq 0$ and are integers

Where

$$
\mathrm{A}_{m \times n}=\left[\begin{array}{ccccccc}
a_{11} & a_{12} & a_{13} & \cdot & \cdot & \cdot & a_{1 n} \\
a_{21} & a_{22} & a_{23} & \cdot & \cdot & \cdot & a_{2 n} \\
a_{31} & a_{32} & a_{33} & \cdot & \cdot & \cdot & a_{3 n} \\
\cdot & \cdot & \cdot & \cdot & \cdot & \cdot & \cdot \\
\cdot & \cdot & \cdot & \cdot & \cdot & \cdot & \cdot \\
\cdot & \cdot & \cdot & \cdot & \cdot & \cdot & \cdot \\
a_{m 1} & a_{m 2} & a_{m 3} & \cdot & \cdot & \cdot & a_{m n}
\end{array}\right] \mathrm{X}
$$

\author{
K.Jeyaraman, PhD. \\ Dean of Science and Humanities, \\ PSNA College of Engineering and Technology, \\ Dindigul-624622, \\ Tamil Nadu, India.
}

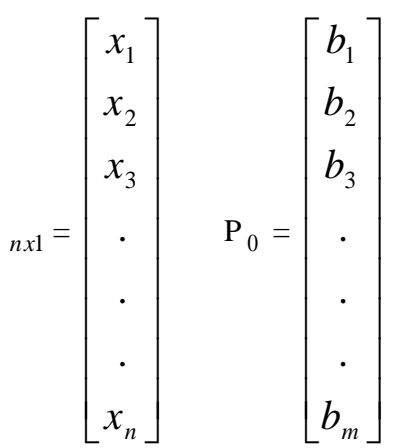

Let the columns corresponding to the matrix A be denoted by $\mathrm{P}_{1}, \mathrm{P}_{2}, \mathrm{P}_{3} \ldots \ldots \mathrm{P}_{n}$ where

$\mathrm{P}_{1}=\left[\begin{array}{c}a_{11} \\ a_{21} \\ a_{31} \\ \cdot \\ \cdot \\ \cdot \\ a_{m 1}\end{array}\right] \mathrm{P}_{2}=\left[\begin{array}{c}a_{12} \\ a_{22} \\ a_{32} \\ \cdot \\ \cdot \\ \cdot \\ a_{m 2}\end{array}\right]$

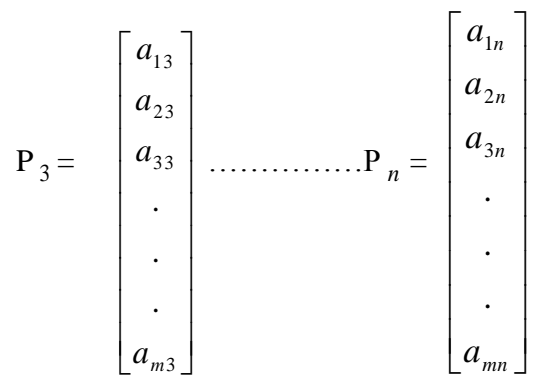

$\mathrm{C}^{T}=\left(\mathrm{c}_{1}, \mathrm{c}_{2}, \mathrm{c}_{3} \ldots . . \mathrm{c}_{n}\right)$,

$\mathrm{D}^{T}=\left(\mathrm{d}_{1}, \mathrm{~d}_{2}, \mathrm{~d}_{3} \ldots . . \mathrm{d}_{n}\right)$ and $\mathrm{c}_{0}, \mathrm{~d}_{0}$ are scalars.

\section{APPROACH}

In this new approach to solve Integer Linear Fractional Programming Problems, three phases are included and those phases are given below.

Phase I:

Promising decision variables are identified to enter in the basis and those promising variables are ordered based on the contribution to the objection function. 


\section{Phase II :}

The arranged promising variables are allowed to enter into the basis in the arranged order after checking whether the newly entering variables will improve the objective function of the problem, keeping the feasibility.

\section{Phase III:}

Finding of the improved solution vector.

The above three phases are repeated till the optimum solution reached.

The step by step procedure is as given below

Step 1: Let iteration $=0$

Step 2 : Perform phase I

Step 3 : Perform phase II

Step 4 : If the set J is empty then , Perform phase III

Step 5 : stop.

\section{Phase I - Ordering of Promising variables}

Step 1 . Using the intercepts of the decision variables along the respective axes with respect to the chosen basis a matrix is called $\theta$ matrix is to be constructed. A typical intercept for the $\mathrm{j}^{\text {th }}$ variable, $\mathrm{x}_{j}$ due to the $\mathrm{i}^{\text {th }}$ the resource, $\mathrm{b}_{i}$ is $\left\{\frac{b_{i}}{a_{i j}}\right\} \mathrm{a}_{i j}>0$

The expanded form of $\theta$ matrix is

$$
\begin{aligned}
& \begin{array}{lllll}
\mathrm{S}_{1} & \mathrm{~S}_{2} \cdot & \mathrm{S}_{i} \cdot & \mathrm{S}_{m}
\end{array}
\end{aligned}
$$

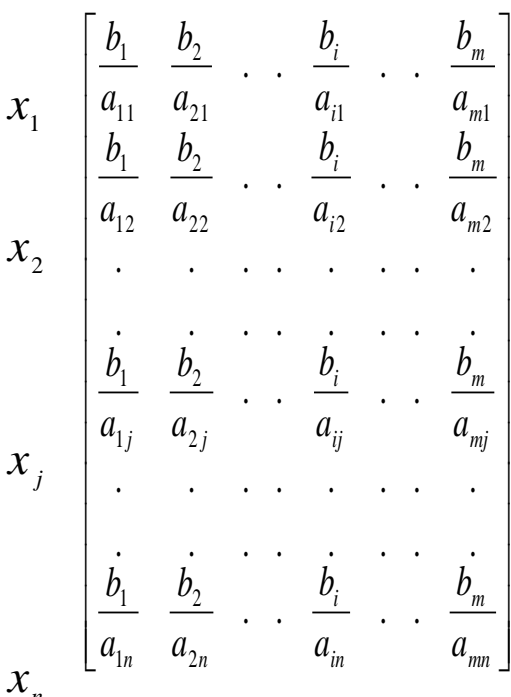

Each row of the $\theta$ matrix consists of m number of intercepts of the decision variable along their respective axes and each column consists of intercepts formed by the number of promising decision variables in each of the $m$ constraints.

Step 2. The minimum intercept and its position in each row of $\theta$ matrix is find out. If there are more one minimum intercept then one of them is selected arbitrarily. Multiply the minimum intercept of the variable corresponding to a row with the corresponding contribution coefficient in the objective function both in the numerator and denominator and the objective function value $\left(\frac{c_{j} x_{j}+c_{0}}{d_{j} x_{j}+d_{0}}\right)$ is calculated.

Step 3. Repeat step2 till the minimum for each row as well as its contribution to the objective function are calculated.

Step 4 . Let $\ell=0$. $\mathrm{J}$ is a set consisting of the subscript of the promising variables.

Step 5 . Select the variable whose $\left(\frac{c_{j} x_{j}+c_{0}}{d_{j} x_{j}+d_{0}}\right)$

value is the largest.If the same largest $\left(\frac{c_{j} x_{j}+c_{0}}{d_{j} x_{j}+d_{0}}\right)$ occurs, for more than one variable then the variable that has maximum contribution including the fractional value is taken as the promising variable.If that is also same then select any one arbitrarily.

Step 6 . Let it be $x_{R}$. Then $x_{R}$ is selected as the promising variable.

Step 7. Increment $\ell$ by 1 .The subscript of the variable $x_{R}$ is stored as the $l^{\text {th }}$ element in set $\mathrm{J}$.

Step 8 . The row corresponding to the variable $x_{R}$ as well as the other rows whose minimum occurs in the column at which the minimum for $x_{R}$ occurs are deleted

Step 9. Step 5 to 8 are repeated till either all the rows or all the columns are deleted.

Step 10. The set of variables collected in Steps 5 to 8 are the ordered promising variables.

Let $J=\{$ Subscripts of the promising variables arranged in the descending

$$
\left.\operatorname{order}\left(\frac{c_{j} x_{j}+c_{0}}{d_{j} x_{j}+d_{0}}\right) \text { value }\right\} \text {. }
$$

Let $\ell$ be the total number of elements in the set $\mathrm{J}$.

\section{Phase II - Arranged variables are allowed to enter into the basis}

The arranged promising variables are allowed to enter into the basis one by one based on the entering criteria.The step by step procedure is given below.

Step 1. Let $k=1, \mathrm{x}_{B}$ is the solution vector and flag $(=0)$ is the flag vector. 


$$
\text { flag }=\left[\begin{array}{c}
\mathrm{O} \\
\mathrm{O} \\
\mathrm{O} \\
\cdot \\
\cdot \\
-
\end{array}\right]_{n \times 1}
$$$$
\mathrm{P}_{0-\text { old }}=\mathrm{P}_{0}
$$

Step 2. Iteration is incremented by 1.

Step 3. The $k^{\text {th }}$ element in the set $\mathrm{J}$ is selected and let it be $\mathrm{j}$. Then the entering variable is $x_{j}$.

Step 4. Computation of $x_{j}$ value.

The value with which $x_{j}$ can enter into the basis is computed by using the following formula

$$
\begin{gathered}
\theta_{k}=\min \left\{\operatorname{int}\left\{\frac{\left(P_{0-o l d}\right)_{i}}{\left(P_{j}\right)_{i}}\right\} ;\right. \\
\left.\left(\mathrm{P}_{j}\right)_{i}>0\right\} \mathrm{i}=1,2,3 \ldots \mathrm{m}
\end{gathered}
$$

Step 5. If $\theta_{k}=1$ and $\mathrm{k}=1$ then the value of $\alpha=1$ else the value of $\alpha$ is chosen between 0 to 1 ( Let $\alpha$ $=0.5$ )

$$
\begin{aligned}
& \text { Compute } S=\operatorname{int}\left(\alpha \theta_{k}\right) \\
& \varepsilon_{k}=\operatorname{int}(1-\alpha) \theta_{k}
\end{aligned}
$$

Step 6. $\mathrm{S}$ is added to the $\mathrm{j}^{\text {th }}$ element of the vector $\mathrm{X}_{B}$ and 1 is added to flag ${ }_{j}$

Step 7. $\mathrm{P}_{0}$ vector is modified using the relation

$$
\begin{gathered}
\left(\mathrm{P}_{0-\text { new }}\right)_{i}=\left(\mathrm{P}_{0-\text { old }}\right)_{i}-\left(\mathrm{P}_{j}\right)_{i} \mathrm{~S} \\
\mathrm{i}=1,2, \ldots \mathrm{m}
\end{gathered}
$$

Step 8. $\left(\mathrm{P}_{0-\text { old }}\right)$ is replaced by $\left(\mathrm{P}_{0-\text { new }}\right)$

If $\mathrm{k}=1$ or $\mathrm{S} \leq 1$ goto step 16

Step 9. Check whether $\mathrm{k}^{\text {th }}$ element is still promising among the remaining list of $(\ell-\mathrm{k})$ promising variables in set $\mathrm{J}$ using the following steps.

Step 10. Let $\mathrm{r}=1$

Step 11. Select the $(\mathrm{k}+\mathrm{r})^{\text {th }}$ element in this set J. Let it be $\mathrm{q}$. Then the variable corresponding position $\mathrm{x}_{q}$.

Step 12. Find $\theta_{q}$ using the formula

$$
\begin{gathered}
\theta_{q}=\min \left\{\operatorname{int}\left\{\frac{\left(P_{0-o l d}\right)_{i}}{\left(P_{j}\right)_{i}}\right\} ;\left(\mathrm{P}_{j}\right)_{i}>0\right\} \\
\varepsilon_{q}=\left(\frac{c_{q} \theta_{q}+c_{0}}{d_{q} \theta_{q}+d_{0}}\right)
\end{gathered}
$$

Step 13. If $\varepsilon_{k}<\varepsilon_{q}$ goto step 15

Step 14. Increment $\mathrm{r}$ by one 16.

If $\mathrm{r} \leq(\ell-\mathrm{k})$ then goto step 11. Else goto step

Step 15. $\mathrm{k}$ is replaced by $\mathrm{k}+\mathrm{r}$ and $\varepsilon_{k}$ is replaced by $\varepsilon_{q}$

If $\mathrm{k}<\ell$ goto step 10

Step 16. If flag $_{k} \leq 1$ goto step 3 .

Else go to Perform Phase I.

Phase III - Determination of new improved ) solution vector to the Integer Linear Fractional Programming Problems

Except for the most promising variable in the solution set obtained in phase II the values of remaining variables are set to zero. Taking this as starting solution, phase I and II are performed until improved solution is obtained. If there is no improvement the next promising variable value along with the most promising variable also is retained and the remaining basic variables made to zero. Phase III is repeated until the basic variables list exhausted.

\section{ALGORITHM}

Stage I. The basic variables are arranged according to the descending order of their contribution to the objective function

Step 1. $\ell=0, \mathrm{k}=0, \mathrm{n}_{1}$ is is the number of basic variables having nonzero values in the solution

Step 2. $\mathrm{X}$ is the solution vector obtained in phase II.

Step 3. If $\ell^{\text {th }}$ element in $\mathrm{X}$, ie $\mathrm{X}_{\ell}>0$, then

$$
\text { Multiply }\left(\frac{c_{\ell} x_{\ell}+c_{0}}{d_{\ell} x_{\ell}+d_{0}}\right) \text {, let it be stored as } \mathrm{k}^{\text {th }}
$$

row $0^{\text {th }}$ column element of array $\mathrm{W}$ and $\ell$ is stored as $\mathrm{k}$ th row $1^{\text {th }}$ column element of array W. $\mathrm{k}$ is incremented by one.

Step 4. $\ell$ is incremented by one

Step 5. If $\ell<\mathrm{n}_{1}$ then goto step 3 .

Step 6. The array $\mathrm{W}$ is sorted in the descending order based on the $0^{\text {th }}$ column values of

$$
\mathrm{W}
$$

Stage II. Finding the solution by assigning all the variable values except one in the basis to zero level.

Step 7. $\mathrm{k}=0$ 
Step 8. $\ell=0$

Step 9. $\mathrm{i}=0$

Step 10. If $\mathrm{i}>\mathrm{k}$ then

$$
\begin{gathered}
\mathrm{J}=\mathrm{W}_{i 1} \\
\mathrm{X}_{j}=0
\end{gathered}
$$

Step 11. i is incremented by one

Step 12. If $\mathrm{i}<\mathrm{n}_{1}$ then goto step 10

Step 13. Now $\mathrm{P}_{c}$ is the current resource vector or ( RHS ) and corresponding objective function value $Z_{1}$ is calculated.

Stage III. Find the new solution

Step 14. Use phase I and phase II and find the new solution $\mathrm{X}$ which is stored as $\mathrm{Y}(\ell)$ and the corresponding objective function value $\mathrm{Z}_{2}$ is stored as $\mathrm{V}$ ( $\ell$ ).

Step 15. $\ell$ is incremented by one

Step 16. If $\ell<\mathrm{n}_{1}$ then goto step 9

Step 17. Find the largest of $\mathrm{V}(\ell)$ and its position pos, where $\left(0 \leq \ell<\mathrm{n}_{1}\right)$, Let it be stored in $\mathrm{Z}_{3}$.

Step 18. If $\mathrm{Z}_{3}>\mathrm{Z}$, then Replace $\mathrm{X}$ by $\mathrm{Y}$ ( pos) goto step 1. else if $k<n_{1}$ then increment $k$ by 1 .goto step 8 .

\section{NUMERICAL EXAMPLE}

Solve the following Integer linear fractional Programming Problem.

Maximize $\mathrm{Z}=$

$\frac{4 x_{1}+17 x_{2}+24 x_{3}+23 x_{4}+19 x_{5}+13 x_{6}+2}{2 x_{1}+3 x_{2}+4 x_{3}+6 x_{4+} 3 x_{5}+3 x_{6}+50}$

Subject to the constraints

$4 \mathrm{x}_{1}+2 \mathrm{x}_{2}+5 \mathrm{x}_{3}+7 \mathrm{x}_{4}+7 \mathrm{x}_{5}+7 \mathrm{x}_{6} \leq 325$

$4 \mathrm{x}_{1}+2 \mathrm{x}_{2}+4 \mathrm{x}_{3}+9 \mathrm{x}_{4}+9 \mathrm{x}_{5}+\mathrm{x}_{6} \leq 400$

$9 \mathrm{x}_{1}+3 \mathrm{x}_{2}+\mathrm{x}_{3}+4 \mathrm{x}_{4}+7 \mathrm{x}_{5}+9 \mathrm{x}_{6} \leq 425$

$5 x_{1}+3 x_{2}+x_{3}+2 x_{4}+4 x_{5}+6 x_{6} \leq 425$

Where $x_{1}, x_{2}, x_{3}, x_{4}, x_{5}, x_{6} \geq 0$ and all are integers

\section{Solution}

$\mathrm{A}=\left(\begin{array}{llllll}4 & 2 & 5 & 7 & 7 & 7 \\ 4 & 2 & 4 & 9 & 9 & 1 \\ 9 & 3 & 1 & 4 & 7 & 9 \\ 5 & 3 & 1 & 2 & 4 & 6\end{array}\right)$

$\mathrm{P}_{0}=\left(\begin{array}{l}325 \\ 400 \\ 425 \\ 425\end{array}\right), \mathrm{P}_{1}=\left(\begin{array}{l}4 \\ 4 \\ 9 \\ 5\end{array}\right), \mathrm{P}_{2}=\left(\begin{array}{l}2 \\ 2 \\ 3 \\ 3\end{array}\right), \mathrm{P}_{3}=\left(\begin{array}{l}5 \\ 4 \\ 1 \\ 1\end{array}\right)$

$\mathrm{X}=\left(\begin{array}{l}x_{1} \\ x_{2} \\ x_{3} \\ x_{4} \\ x_{5} \\ x_{6}\end{array}\right), \mathrm{P}_{4}=\left(\begin{array}{l}7 \\ 9 \\ 4 \\ 2\end{array}\right), \mathrm{P}_{5}=\left(\begin{array}{l}7 \\ 9 \\ 7 \\ 4\end{array}\right), \mathrm{P}_{6}=\left(\begin{array}{l}7 \\ 1 \\ 9 \\ 6\end{array}\right)$

$\mathrm{C}^{\mathrm{T}}=(4,17,24,23,19,13), \mathrm{D}^{\mathrm{T}}=(2,3,4,6,3,5,50), \mathrm{C}_{0}=2$, $\mathrm{D}_{0}=50$.

\section{Phase - I}

To find $\theta$ Matrix

$d_{j} \quad c_{j} x_{j}$

$\theta=$

$\begin{array}{lllllll}2 & 4 & x_{1}\end{array}\left[\begin{array}{llll}81.25 & 100.00 & \mathbf{4 7 . 2 2} & 85.00\end{array}\right]$

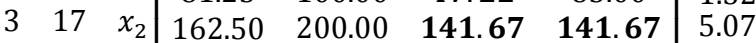

\begin{tabular}{lll|llllll}
4 & 24 & $x_{3}$ & $\mathbf{6 5 . 0 0}$ & 100.00 & 425.00 & 425.00 & 5.04
\end{tabular}

\begin{tabular}{lll|llllll}
6 & 23 & $x_{4}$ & 46.43 & $\mathbf{4 4 . 4 4}$ & 106.25 & 212.50 & 3.23
\end{tabular}

\begin{tabular}{lll|llllll}
3 & 19 & $x_{5}$ & 46.43 & $\mathbf{4 4 . 4 4}$ & 60.71 & 106.25 & 4.62
\end{tabular}

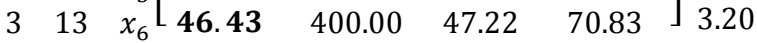
Arrangement of promising variables $\mathrm{J}=\{2,3,5\}$

Phase - II

$\mathrm{X}_{2} \rightarrow$ promising variable

$\theta=\operatorname{minimum}\left\{\operatorname{int}\left(\frac{325}{2}, \frac{400}{2}, \frac{425}{3}, \frac{425}{3}\right)\right\}=$ minimum $(162,200,141,141)=141$

$\therefore \mathrm{S}=70$

$\mathrm{Z}=\frac{1190+2}{210+50}=\frac{1192}{260}=4.581$

$\left(\mathrm{P}_{0}-\text { new }\right)_{1=} 325-70 \times 2=185$

$\left(\mathrm{P}_{0}-\text { new }\right)_{2}=400-70 \times 2=260$

$\left(\mathrm{P}_{0}-\text { new }\right)_{3}=425-70 \times 3=215$

$\left(\mathrm{P}_{0}-\text { new }\right)_{4}=425-70 \times 3=215$

$\mathrm{X}_{2} \rightarrow$ promising variable

$\theta=\operatorname{minimum}\left\{\operatorname{int}\left(\frac{185}{2}, \frac{260}{2}, \frac{215}{3}, \frac{215}{3}\right)\right\}=$ minimum $(92,130,71,71)=71$

$\therefore \mathrm{S}=35$

$\mathrm{Z}=\frac{17 \times 35+1192}{3 \times 35+260}=4.90$

$\left(\mathrm{P}_{0}-\text { new }\right)_{1}=115,\left(\mathrm{P}_{0}-\text { new }\right)_{2}=190$,

$\left(\mathrm{P}_{0}-\text { new }\right)_{3}=110,\left(\mathrm{P}_{0}-\text { new }\right)_{4}=110$

$\mathrm{X}_{2} \rightarrow$ promising variable

$\theta=\operatorname{minimum}\left\{\operatorname{int}\left(\frac{115}{2}, \frac{190}{2}, \frac{110}{3}, \frac{110}{3}\right)\right\}$

$=\operatorname{minimum}(57,95,36,36)=36$

$\therefore \mathrm{S}=18$

$\mathrm{Z}=\frac{17 \times 18+1787}{3 \times 18+365}=5.00$

$\left(\mathrm{P}_{0}-\text { new }\right)_{1}=79,\left(\mathrm{P}_{0}-\text { new }\right)_{2}=154,\left(\mathrm{P}_{0}-\text { new }\right)_{3}=56,\left(\mathrm{P}_{0}-\right.$ new $)_{4}=56$

$\mathrm{X}_{3} \rightarrow$ promising variable

$\theta=\operatorname{minimum}\left\{\operatorname{int}\left(\frac{79}{5}, \frac{152}{4}, \frac{56}{1}, \frac{56}{1}\right)\right\}$

$=\operatorname{minimum}(15,38,56,56)=15$

$\therefore \mathrm{S}=7$

$\mathrm{Z}=\frac{7 \times 24+2093}{7 \times 4+419}=5.06$

$\left(\mathrm{P}_{0}-\text { new }\right)_{1}=44,\left(\mathrm{P}_{0}-\text { new }\right)_{2}=126,\left(\mathrm{P}_{0}-\text { new }\right)_{3}=49,\left(\mathrm{P}_{0}-\right.$ new $)_{4}=49$

$\mathrm{X}_{3} \rightarrow$ promising variable

$\theta=\operatorname{minimum}\left\{\operatorname{int}\left(\frac{44}{5}, \frac{126}{4}, \frac{49}{1}, \frac{49}{1}\right)\right\}$

$=\operatorname{minimum}(8,31,49,49)=8$ 
$\therefore \mathrm{S}=4$

$\mathrm{Z}=\frac{4 \times 24+2261}{4 \times 4+447}=\frac{2357}{463}=5.09$

$\left(\mathrm{P}_{0}-\text { new }\right)_{1}=24,\left(\mathrm{P}_{0}-\text { new }\right)_{2}=110,\left(\mathrm{P}_{0}-\text { new }\right)_{3}=45,\left(\mathrm{P}_{0}-\right.$

new $)_{4}=45$

$\mathrm{X}_{3} \rightarrow$ promising variable

$\theta=\operatorname{minimum}\left\{\operatorname{int}\left(\frac{24}{5}, \frac{110}{4}, \frac{45}{1}, \frac{45}{1}\right)\right\}$

$=\operatorname{minimum}(4,27,45,45)=4$

$\therefore \mathrm{S}=2$

$\mathrm{Z}=\frac{2 \times 24+2357}{2 \times 4+463}=5.11$

$\left(\mathrm{P}_{0}-\text { new }\right)_{1}=14,\left(\mathrm{P}_{0}-\text { new }\right)_{2}=102,\left(\mathrm{P}_{0}-\text { new }\right)_{3}=43,\left(\mathrm{P}_{0}-\right.$

new $)_{4=} 43$

The current solution is $x_{2}=123, x_{3}=13$

$\mathrm{Z}=\frac{123 \times 17+24 \times 13+2}{3 \times 123+4 \times 13+50}=\frac{2405}{471}=5.11$

Repeating this procedures Phase I and Phase II we get the solution as

The current solution is $\mathrm{x}_{2}=130, \mathrm{x}_{3}=13$

$\mathrm{Z}=\frac{130 \times 17+24 \times 13+2}{3 \times 130+4 \times 13+50}=\frac{2524}{492}=5.13$

\section{Phase - III}

$\mathrm{x}_{2}$ is retained 130 and remaining variables are set to zero ,that is $\mathrm{x}_{3}=0$.

$$
\text { Now } P_{0}=\left(\begin{array}{c}
65 \\
140 \\
35 \\
35
\end{array}\right)
$$

Following similarly we get the final solution the optimal solution is

$$
\mathrm{x}_{2}=130, \mathrm{x}_{3}=13
$$

$\operatorname{MaxZ}=\frac{130 \times 17+24 \times 13+2}{3 \times 130+4 \times 13+50}=\frac{2524}{492}=\mathbf{5 . 1 3}$

\section{CONCLUSION}

In this a new approach to solve Integer Linear Fractional Programming problem has been discussed. The above algorithm rendered best optimal solution. In Future this method can be applied in Zero-One Integer Linear Fractional Programming to get better optimal solution.

\section{ACKNOWLEDGEMENT}

My sincere thanks to my guide Dr.K.Jeyaraman \& Dr.S.Sakthivel Principal, PSNA-CET-DGL. I whole heartly thank for the cooperation rendered by my wife Mrs.S.Jayalakshmi.

\section{REFERENCES}

[1] C.Audet, P.Hansen, B.Jaumard and G.Savard, Journal of Optimization theory and Application. Vol.93, No.2, (1997) 273-300.

[2] A.I.Barros, J.B.G. Frenk, S.Schaible and S. Zhang, A new algorithm for generalized fractional programs Mathematical Programming 72 (1996), 2, 147-175.

[3] A.Charles, W.W. Cooper An explicit general solution in linear fractional programming, Vol.20 449-467 September 1973.

[4] Erik B.Bajalinov Linear Fractional programming theory, methods, Applications and Siftware.

[5] Fengquiyou \& Ignacio Grossmam. Solving MixedInteger Linear Fractional Programming Problems with Dinkelbach's Algorithm and MINLP methods

[6] Hamdy A.Taha, "Operations Research- An Introduction", Seventh Edition, Prentice-Hall of India Private Limited, 2004

[7] H.Ishii, T. Ibaraki and H.Mine, Fractional knapsack problems, Mathematical Programming 13 (1976), 3 , 255-271.

[8] Kanti Swarup, Gupta P.K.Manmohan, "Operations Research", Sultan Chand and Sons,2010.

[9] G.KarthiKeyan,"Design of a new computer oriented algorithm to solve linear programming problems", Ph.D., thesis, Alagappa University, India, May 2011.

[10] Stancu-Minasian, I.M. Fractional programming theory, methods and applications series, Mathematics and its Application Vol. 409 (1997)432p.

[11] Suresh Chandra, M. Chandra Mohan, A note on integer linear fractional programming, Volume 27 (1980)171-174.

[12] L.Vicente, G.Savard and S.Judics, Journal of Optimization Theory and Applications, 89, No.3 (1996) 597-614.

[13] Wukfred Candler and Robert Townsley, Computers and Operations Research, 9(1982) 59-76. 